\title{
Individualism and insulin pump therapy
}

\author{
D. Kerr
}

Received: 22 October 2008 /Accepted: 28 October 2008 / Published online: 26 November 2008

(C) Springer-Verlag 2008

To the Editor: Nowadays, so-called 'smart' insulin pumps invariably have built-in features that are perceived to add benefit for users. These include: dosage calculators that manage the complex arithmetic associated with pump use; an 'insulin-on-board' feature that considers the amount of insulin still 'active' in a patient prior to recommending an insulin dosage; and the ability to programme alternative basal insulin delivery rates for corresponding times of the day and night and for different types of bolus infusion according to variations in types of foods and meal content. Other features include programmable reminders and alerts, carbohydrate databases, and so on. The increasing complexity of pumps is partly an attempt to give manufacturers a 'market edge' against their competitors. However, the evidence base (i.e. randomised controlled clinical trials) for including such features is generally lacking.

In Bournemouth, UK, we provide a dedicated 2 day group education programme for commencement of insulin pump therapy. The programme is run by trained nurse educators and dietitians. It uses a structured curriculum approach and covers all aspects of pump therapy, including the 'smart' features. Consistent with published data, we have found that the use of insulin pump therapy is associated with sustained improvements in $\mathrm{HbA}_{1 \mathrm{c}}$ levels, fewer hypoglycaemic episodes, enhanced early warning symptoms of impending low blood glucose levels and an improved quality of life [1-4].

Recently we have incorporated insulin pump download software into our routine clinical practice. This has the potential to provide greater insights into an individual's use of these complex technological features. Despite identical training, pump-users seem to prefer a simple and individual

\section{Kerr $(\bowtie)$}

Bournemouth Diabetes \& Endocrine Centre,

Royal Bournemouth Hospital,

Bournemouth, Dorset BH7 7DW, UK

e-mail: david.kerr@rbch.nhs.uk approach to insulin delivery (Fig. 1). Not using all of the technological aspects of the pump may be a consequence of a failure to understand how to use the features in the first place. Alternatively, patients may feel that specific features
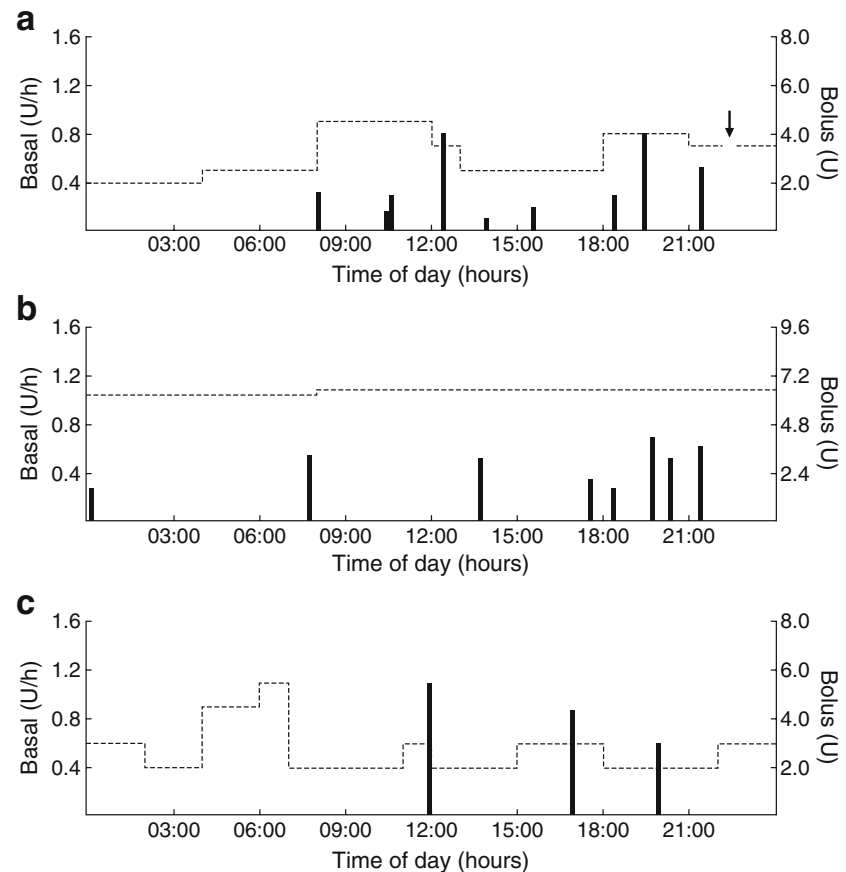

Fig. 1 Solutions downloads for Medtronic insulin pump devices (Medtronic, Northridge, CA, USA) indicating basal infusion rates (dotted line), bolus infusions of insulin (bars) and interruption of insulin infusions (arrow) over $24 \mathrm{~h}$ time periods for three patients. None of the patients (or relatives/carers) reported hypoglycaemia to be a problem. a Patient started subcutaneous insulin infusion (CSII) in 2007 and achieved $\mathrm{HbA}_{1 \mathrm{c}} 8.2 \%$. The patient has programmed seven changes of basal infusion rates over $24 \mathrm{~h}$ with multiple meal time bolus infusions and between-meal corrections. b Patient started CSII in 2005 and achieved $\mathrm{HbA}_{1 \mathrm{c}}$ 7.6\%. Here the patient has only two basal infusion rates, but uses multiple bolus infusions including between-meal corrections over a $24 \mathrm{~h}$ period. c Patient started CSII in 2007 and achieved $\mathrm{HbA}_{1 \mathrm{c}}$ 7.5\%. This patient has programmed nine changes of basal infusion rates over $24 \mathrm{~h}$ but with pre-meal boluses only 
do not give added value in terms of the time and effort involved. It is also possible that patients may use some of the features on an ad hoc basis, and so the use of the features may be missed by the download period (usually 2 weeks). Anecdotally this does not seem to be the case.

It does seem important that pump manufacturers invest in research to show that additional pump facilities add value for individuals living with type 1 diabetes. Perhaps simpler pumps could produce similar benefits but at lesser cost?

Acknowledgement No funding sources were involved.

Duality of interest D. Kerr has received honoraria for contributing to education programmes supported by Medtronic.

\section{References}

1. Pickup J, Mattock M, Kerry S (2002) Glycaemic control with continuous subcutaneous insulin infusion compared with intensive injections in patients with type 1 diabetes: meta-analysis of randomised controlled trials. BMJ 324:705-711

2. Weissberg-Benchell J, Antisdel-Lomaglio J, Seshadri R (2003) Insulin pump therapy - a meta-analysis. Diabetes Care 26:10791087

3. Pickup JC, Sutton AC (2008) Severe hypoglycaemia and glycaemic control in type 1 diabetes: meta-analysis of multiple daily insulin injections versus continuous subcutaneous insulin infusion. Diabetic Med 25:765-774

4. Kerr D, Nicholls H, James J (2008) Continuous subcutaneous insulin infusion (CSII: insulin pump therapy): a Bournemouth perspective. Pract Diabetes Int 25:114-117 